\title{
(2) OPEN ACCESS \\ Mixed-methods process evaluation of SafeTea: a multimedia campaign to prevent hot drink scalds in young children and promote burn first aid
}

\author{
Laura Elizabeth Cowley $\left(\mathbb{1},{ }^{1}\right.$ C Verity Bennett $\left(\mathbb{0},{ }^{1}\right.$ Isabelle Brown, ${ }^{2}$ Alan Emond, ${ }^{3}$ \\ Alison Mary Kemp
}

- Additional material is published online only. To view please visit the journal online (http://dx.doi.org/10.1136/ injuryprev-2020-043909).

${ }^{1}$ Division of Population Medicine, Cardiff University, Cardiff, UK

${ }^{2}$ Scar Free Foundation, London, UK

${ }^{3}$ Centre for Academic Child Health, University of Bristol, Bristol, UK

\section{Correspondence to}

Dr Laura Elizabeth Cowley, Division of Population Medicine, Cardiff University, Cardiff CF10 3AT, UK; CowleyLE@cardiff. ac.uk

Received 2 July 2020

Revised 27 August 2020

Accepted 30 August 2020

\section{ABSTRACT}

Objectives SafeTea is a multifaceted intervention delivered by community practitioners to prevent hot drink scalds to young children and improve parents' knowledge of appropriate burn first aid. We adapted SafeTea for a national multimedia campaign, and present a mixed-methods process evaluation of the campaign. Methods We used social media, a website hosting downloadable materials and media publicity to disseminate key messages to parents/caregivers of young children and professionals working with these families across the UK. The SafeTea campaign was launched on National Burns Awareness Day (NBAD), October 2019, and ran for 3 months. Process evaluation measurements included social media metrics, Google Analytics, and quantitative and qualitative results from a survey of professionals who requested hard copies of the materials via the website.

Results Findings were summarised under four themes: 'reach', 'engagement', 'acceptability' and 'impact/ behavioural change'. The launch on NBAD generated widespread publicity. The campaign reached a greater number of the target audience than anticipated, with over 400000 views of the SafeTea educational videos. Parents and professionals engaged with SafeTea and expressed positive opinions of the campaign and materials. SafeTea encouraged parents to consider how to change their behaviours to minimise the risks associated with hot drinks. Reach and engagement steadily declined after the first month due to reduced publicity and social media promotion.

Conclusion The SafeTea campaign was successful in terms of reach and engagement. The launch on NBAD was essential for generating media interest. Future campaigns could be shorter, with more funding for additional social media content and promotion.

\section{INTRODUCTION}

Scalds from hot drinks are a major paediatric public health concern. ${ }^{1-3}$ Hot drinks account for $55 \%$ of scald injuries in children less than 5 years old, ${ }^{1}$ resulting in an estimated 30 children per day in the UK attending hospital for treatment. ${ }^{4}$ The most common mechanism is a pull-down injury, whereby a child reaches up and pulls a hot drink down over themselves. ${ }^{1}$ These injuries may cause permanent scarring and long-term psychosocial and mental health difficulties, ${ }^{56}$ yet they are entirely preventable.
While primary prevention is the priority, immediate appropriate first aid administered by a caregiver can mitigate the devastating effects of scald injuries and improve clinical outcomes by facilitating healing and reducing injury severity and the extent of treatment required. ${ }^{7}$ Evidence-based burn first aid is simple: COOL the burn with cool running water for $20 \mathrm{~min}$, CALL for medical assistance or advice and COVER the burn with cling film. ${ }^{8} 9$ Nevertheless, only $25 \%-28 \%$ of children with a burn receive optimal first aid before they present to the emergency department. ${ }^{8}{ }^{10}$ Parents have limited knowledge of the appropriate first aid treatment for burns, ${ }^{11-13}$ online information regarding burn first aid is inconsistent and inaccurate, ${ }^{14} 15$ and inappropriate or harmful home remedies are often used. ${ }^{8} 12$

There are few interventions aiming to prevent hot drink scalds in children, ${ }^{16-18}$ and limited research into effective burn first aid education for caregivers, although there is evidence that educational interventions may improve caregivers' knowledge of appropriate burn first aid, at least in the short term. ${ }^{19}$ 'SafeTea' is a community-based, multifaceted intervention designed for delivery by early-years practitioners. ${ }^{20}$ SafeTea uses a variety of bespoke materials and teaching activities to disseminate consistent key prevention and first aid messages in a range of environments (homes, parenting groups and childcare settings). ${ }^{20}$ SafeTea has been demonstrated to be feasible in a smallscale community setting. ${ }^{20}$ The bespoke materials and teaching activities were acceptable to parents and community practitioners, improved parents' knowledge of the risk factors for hot drink scalds and appropriate burn first aid, and demonstrated potential to change caregivers behaviours with regards to hot drink scalds prevention and burn first aid. ${ }^{20}$

SafeTea was developed into a national integrated multimedia campaign, using social media, a dedicated website (www.safetea.org.uk) hosting information and free downloadable materials, digital advertising, targeted promotion to professionals working with parents of young children, and national and local television, radio, and press publicity. The SafeTea intervention materials were modified where necessary according to feedback from the feasibility study, ${ }^{20}$ reproduced with new branding and adapted for online delivery. The multimedia approach was chosen to disseminate the 


\section{Box 1 The five key SafeTea messages}

- Keep hot drinks out of reach of young children.

- Never pass a hot drink over the heads of children.

- Never hold a baby and a hot drink at the same time.

- Create a SafeTea area at home where hot drinks are made and drink them safely away from children.

- Burn first aid: Cool, Call, Cover.

SafeTea key messages to as many caregivers of young children as possible, and to encourage professionals to deliver the intervention and promote SafeTea messages in their own settings. Online delivery enabled data collection for a process evaluation to understand not only whether the campaign was successful, but how and why it was successful. ${ }^{21} 22$ Google Analytics and social media metrics have been established as useful process evaluation measurements for online health promotion campaigns. ${ }^{23} 24$

This paper describes the design and development of the SafeTea campaign and reports a mixed-methods process evaluation of the campaign, to: (1) measure the reach of the campaign, (2) evaluate parents and professionals engagement with SafeTea and determine which components generated the most engagement, (3) evaluate the acceptability of SafeTea to parents and professionals, (4) assess the impact of SafeTea on parents knowledge and behaviours with regards to hot drink scalds prevention and burn first aid and (5) pinpoint strengths and weaknesses in the campaign strategy and implementation to identify areas for improvement.

\section{METHODS}

Design and development of the SafeTea multimedia campaign SafeTea had five key messages (box 1) and was targeted at parents/caregivers of children aged $<5$ years, and community practitioners (eg, parent group staff, health visitors) working with these parents/caregivers. The logic model for the SafeTea campaign is shown in figure 1 . The intervention is based on behavioural change theories including the health belief model, ${ }^{25}$ protective motivation ${ }^{26}$ and social cognitive theory, ${ }^{27}$ and aims to modify caregiver's beliefs about the risks and severity of hot drink scalds, and their self-efficacy for preventing them and mitigating their severity using appropriate first aid.

A steering group of researchers, national injury prevention charities and public health organisations informed the development and implementation of the campaign (figure 2). These collaborating partners were invited to support, inform and promote the campaign as they shared an interest in burns prevention and first aid. They came on board to boost the profile of SafeTea and help to increase reach and engagement. The steering group attended monthly meetings, and members suggested materials and dissemination methods, promoted SafeTea via their existing social media profiles, contacts and networks, shared their experiences of promoting campaigns and shared their own resources. In addition, charities and organisations signed up as Ambassadors and promoted SafeTea messages in blogs, e-news and via Twitter. Raw Marketing (www.raw-marketing.co.uk) designed the marketing strategy and SafeTea branding and collaborated with the Children's Burns Trust to coordinate the launch on National Burns Awareness Day (NBAD).

SafeTea social media accounts were established on Facebook, Instagram and Twitter. These platforms were selected due to their popularity with the target audience. ${ }^{28} 29$ One author (IB) managed the social media accounts part-time from September 2019-January 2020. She finalised and scheduled the social media posts using the Hootsuite social media management tool, and responded to comments. There were 3-4 social media posts per day in October, and 1-2 from November onwards. Posts were designed to deliver the key messages and to guide social media users to the dedicated website www.safetea.org.

\begin{tabular}{|c|c|c|c|c|}
\hline $\begin{array}{c}\text { SafeTea online } \\
\text { Intervention Inputs }\end{array}$ & $\begin{array}{l}\text { SafeTea online } \\
\text { Intervention } \\
\text { Processes }\end{array}$ & $\begin{array}{c}\text { Intermediate } \\
\text { Outcomes: Perception } \\
\text { / Knowledge }\end{array}$ & $\begin{array}{c}\text { Intermediate } \\
\text { Outcomes: Behaviour }\end{array}$ & $\begin{array}{c}\text { Outcomes: Pre-school } \\
\text { Burns }\end{array}$ \\
\hline $\begin{array}{l}\text { 1. Expertise provided by a } \\
\text { steering group of } \\
\text { collaborating partners } \\
\text { 2. Social media accounts } \\
\text { branded with SafeTea logos \& } \\
\text { messaging } \\
\text { 3. Dedicated SafeTea website } \\
\text { hosting information \& free } \\
\text { downloadable materials } \\
\text { 4. Intervention materials: } \\
\text { tested \& professionally } \\
\text { produced posters, magnets, } \\
\text { reach charts, leaflets \& } \\
\text { activity sheets; custom-made } \\
\text { prevention \& first aid videos } \\
\text { 5. Marketing strategy } \\
\text { designed by a professional } \\
\text { marketing company }\end{array}$ & $\begin{array}{l}\begin{array}{l}\text { National, UK-wide delivery of } \\
\text { consistent \& repeated messages } \\
\text { froma range of sources \& } \\
\text { methods }\end{array} \\
\text { 1. Ambassadors } \\
\text { 2. Social media posts }-3 \text { months } \\
\text { 3. Promotion to professionals } \\
\text { 4. Digital advertising } \\
\text { 5. Launch on National Burns } \\
\text { Awareness Day } \\
\text { 6. TV, radio, and other publicity } \\
\text { 7. Professionals delivering the } \\
\text { intervention in their own } \\
\text { settings: Group \& one-to-one } \\
\text { discussions, interactive } \\
\text { demonstrations, fridge magnets } \\
\text { \& flyers handed out \& } \\
\text { displayed, posters \& reach } \\
\text { charts displayed }\end{array}$ & $\begin{array}{l}\text { 1. Increased perceived risk of } \\
\text { hot drink scald injury } \\
\text { 2. Increased perceived } \\
\text { severity of hot drink scald } \\
\text { injury } \\
\text { 3. Increased knowledge of } \\
\text { correct first aid } \\
\text { 4. Perceived effectiveness of } \\
\text { prevention behaviour } \\
\text { 5. Perceived effectiveness of } \\
\text { correct first aid } \\
\text { 6. Self-efficacy in prevention } \\
\text { behaviours } \\
\text { 7. Self-efficacy in first aid }\end{array}$ & $\begin{array}{l}\text { 1. Keeping hot drinks out } \\
\text { of reach of children } \\
\text { 2. Not passing a hot drink } \\
\text { over a child } \\
\text { 3. Not holding a hot drink } \\
\text { whilst holding a child } \\
\begin{array}{l}\text { 4. Increase in correct } \\
\text { burns first aid treatment } \\
\text { by caregiver }\end{array}\end{array}$ & $\begin{array}{l}\text { 1. Reduced incidence of } \\
\text { burns in pre-school aged } \\
\text { children }\end{array}$ \\
\hline \multicolumn{5}{|c|}{$\begin{array}{l}\text { Context: Injury prevention in children aged less than } 5 \text { is a public health priority; Hot drinks in the UK are an accepted feature of everyday } \\
\text { life; There is a lack of knowledge of appropriate burn first aid in the target population; Ineffective or harmful traditional remedies for burns } \\
\text { are passed down by families; Social media platforms offer the opportunity to disseminate SafeTea key messages nationally and reach the } \\
\text { current 'internet generation' of parents/caregivers of young children } \\
\text { Assumptions: Reach - the intervention reaches the target population (parents/caregivers of young children across the UK ano } \\
\text { professionals working with these parents/caregivers); Engagement-parents and professionals engage with the intervention and spread } \\
\text { the Safe Tea messages to others; Mechanisms of change-parents/caregivers of young children show the expected improvements in thei } \\
\text { beliefs, knowledge, self-efficacy and behaviours relating to hot drink scalds prevention and burn first aid }\end{array}$} \\
\hline
\end{tabular}

Figure 1 Logic model for the SafeTea campaign. 


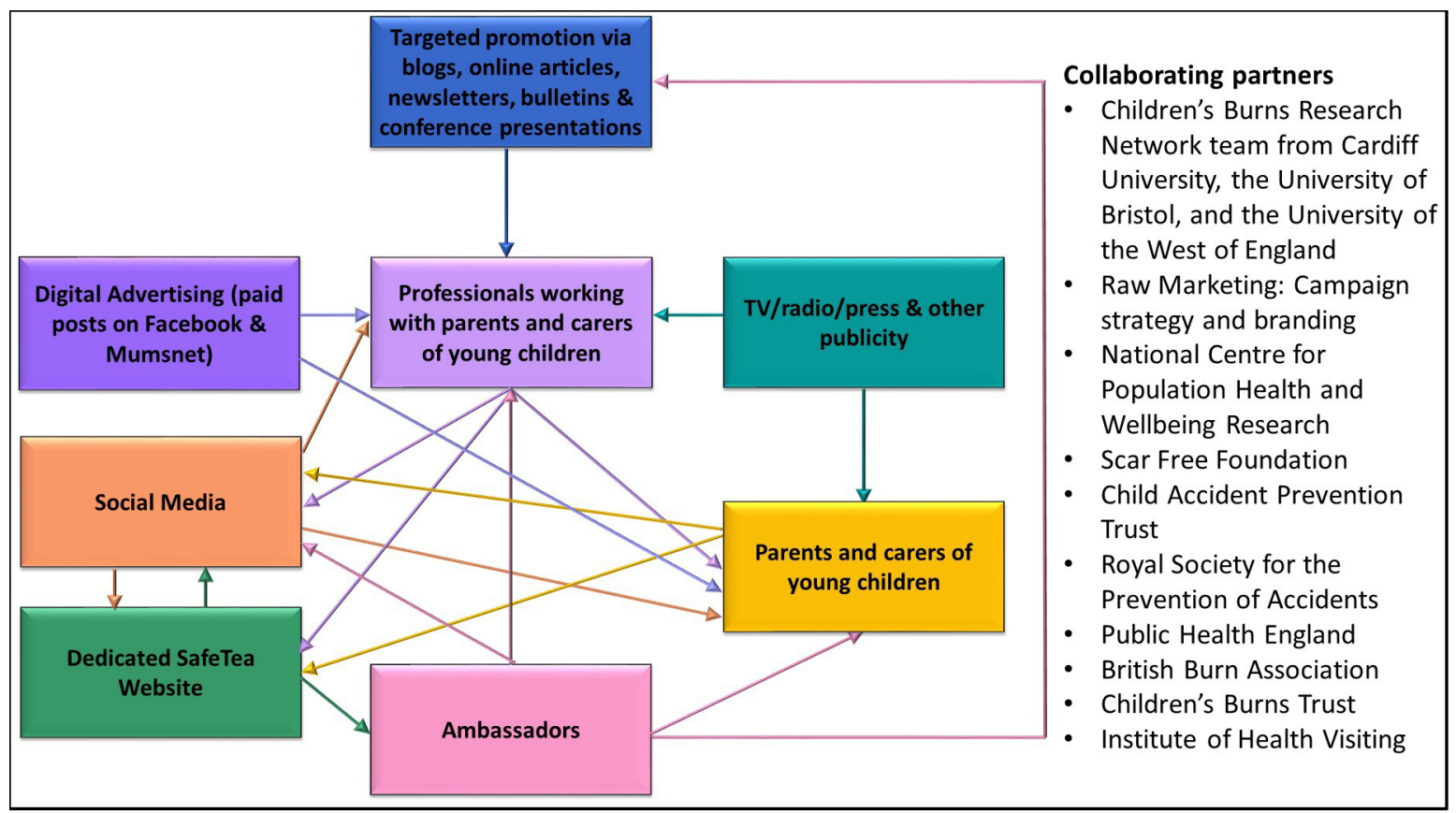

Figure 2 The relationships between the different components of the SafeTea campaign and a list of collaborating partners. TV, television.

uk, where they could find custom-made educational videos and cut-downs, and free downloadable materials in English: posters, flyers, magnets, reach charts, activity sheets and digital logos and banners (online supplemental appendix 1). All printed materials used in the campaign had been tested in the feasibility study. ${ }^{20}$ Some were modified according to feedback, ${ }^{20}$ for example, the first aid magnet was made larger and the prevention message was added, and additional posters were created with a range of different images. All materials were professionally reproduced by a graphic designer, with new branding (a new SafeTea logo, colour scheme and standardised graphics). The branding was part of the marketing strategy designed by Raw Marketing to create an effective online presence and in turn maximise reach on social media. Finally, the materials were adapted so that they could be downloaded and printed from the SafeTea website. Free resource packs of printed materials were available for professionals to request via the website, to facilitate intervention delivery in their own settings. The custom-made videos were produced in collaboration with a professional film company, and featured an adult discussing their life experiences after sustaining a scald in childhood, and an emergency department doctor discussing appropriate burn first aid.

Digital advertising during the SafeTea campaign included 2 months of paid posts on Facebook designed to reach a minimum of 5500 UK parents per day, and 1 month of paid adverts on Mumsnet (www.mumsnet.com) designed to target mums with young children. Targeted promotion via blogs, online articles, newsletters, bulletins and conference presentations was used to brief professional groups (eg, health visitors, childminders, paediatricians) working with families about the campaign and materials, and encourage them to deliver the intervention to parents in their own settings (online supplemental appendix 2). The SafeTea campaign was launched on NBAD, 16 October 2019, with coordinated and widely circulated public relations press releases, and ran for 3 months. Two volunteers recruited through the Children's Burns Trust publicised their personal stories which were used as 'case studies' to attract media interest. These included a story from a mother about her toddler who was scalded by hot coffee, and a story from a young father who sustained a serious scald injury in childhood.

Several cafés signed up via the website to promote the campaign. A number of National Childbirth Trust baby cafés were contacted and asked to support the campaign, however, no responses were received. Consideration was given to advertising SafeTea in general practitioner surgeries, however, this method was too costly.

Figure 2 illustrates the relationships between the campaign components and figure 3 details activities undertaken during the design and development of SafeTea.

\section{Process evaluation measurements}

The evaluation was informed by the Medical Research Council guidance for process evaluations of complex interventions, ${ }^{21}$ and the intervention mapping framework, ${ }^{30}$ which recommend that the evaluation design, data collection and analysis are based on the underlying theory of how an intervention works. The evaluation strategy was, therefore, underpinned by the inputs, processes and assumptions detailed in the logic model (figure 1).

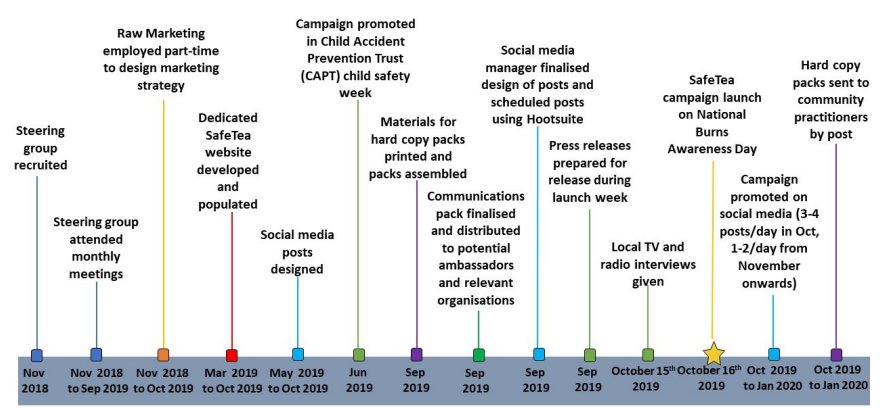

Figure 3 A timeline of activities undertaken during the design and development of the SafeTea campaign. TV, television. 
The process evaluation used a mixed-methods approach consisting of five components: (1) an appraisal of the publicity generated by the launch on NBAD, (2) the metrics of reach, impressions and engagement from the SafeTea social media accounts and Mumsnet, (3) the analytics from the website usage, (4) quantitative and qualitative analysis of an online survey of professionals who requested free resource packs via the website and (5) qualitative analysis of social media users comments on the campaign. Website and social media data were collected for the period October 2019-January 2020, from Google Analytics, Twitter Analytics and Facebook Insights.

Reach on Facebook and potential reach on Twitter was defined as the total number of people who saw (or potentially saw) any SafeTea content. Impressions on Twitter were the total number of times any SafeTea content was seen. Engagement on social media referred to any interaction with a social media account or page, and was measured using metrics such as likes, follows, reactions, retweets, comments and shares. Engagement rate on Twitter was calculated by dividing engagement (likes, retweets, etc) by the total number of impressions during the 3-month campaign period.

The survey was created using 'Online surveys' (www.onlinesurveys.ac.uk). When requesting free resource packs via the SafeTea website, professionals were required to indicate whether they would complete an anonymous online survey (online supplemental appendix 3). The survey link was emailed to those who consented, in February 2020, to evaluate the use and impact of the SafeTea materials, and to assess the professionals' opinions of the campaign and materials. The survey remained live for
1 month before it was closed, during which, two reminder emails were sent to encourage responses.

\section{Analysis}

A triangulation approach was used to integrate the results from the five data sources, to provide a comprehensive overview of the findings and enhance confidence in the conclusions. ${ }^{31} 32$ One author (IB) conducted a comprehensive social media evaluation and extracted the key social media metrics. The lead author (LEC) extracted the SafeTea website usage statistics using Google Analytics, analysed the quantitative survey data and undertook a qualitative analysis of survey respondents' and social media users' free-text comments using thematic analysis. ${ }^{33}$ The lead author then categorised and summarised the data from the different sources according to themes corresponding to the evaluation goals. Thematic analysis of the qualitative data entailed grouping codes into categories, and arranging categories under the a priori overarching evaluation themes. Findings were discussed at research team meetings and any disagreements regarding data interpretation were resolved by consensus. An analytical framework was developed; categories and their definitions are detailed in the framework (table 1). Qualitative data were summarised using indicative quotations (box 2). Quantitative data were summarised using counts, frequencies and proportions.

\section{RESULTS}

\section{Reach of the SafeTea campaign}

The SafeTea launch on NBAD reached 50000 people on Facebook and attracted widespread publicity via media coverage on

Table 1 Analytical framework for the qualitative analysis of survey respondents' and social media users' comments on the SafeTea campaign and materials

\begin{tabular}{|c|c|c|}
\hline Theme & Category & Definition \\
\hline \multirow[t]{3}{*}{ Reach } & $\begin{array}{l}\text { Professionals proactivity in spreading the SafeTea } \\
\text { messages }\end{array}$ & $\begin{array}{l}\text { Any comments by professionals about how they used the SafeTea materials to deliver the } \\
\text { intervention in their own settings and spread the SafeTea messages to their colleagues and to } \\
\text { parents/caregivers of young children. Any comments on social media promoting the campaign or } \\
\text { encouraging others to interact with (eg, share) SafeTea posts. }\end{array}$ \\
\hline & Longevity of the SafeTea campaign & $\begin{array}{l}\text { Any comments by professionals regarding the continued use of the SafeTea materials after the } \\
\text { end of the 3-month campaign. }\end{array}$ \\
\hline & $\begin{array}{l}\text { Professionals use of initiative in spreading the } \\
\text { SafeTea messages }\end{array}$ & $\begin{array}{l}\text { Any remarks by professionals about actions they have taken in order to continue using the } \\
\text { materials to deliver the intervention and spread the SafeTea messages in their own settings. }\end{array}$ \\
\hline Engagement & $\begin{array}{l}\text { Components of the SafeTea intervention (printed } \\
\text { materials, activities, videos) that parents and } \\
\text { professionals were most engaged with }\end{array}$ & $\begin{array}{l}\text { Any comments about which of the SafeTea materials or components of the intervention } \\
\text { that professionals and parents/caregivers were most engaged with and why. Any remarks } \\
\text { by professionals regarding the practicality of delivering the SafeTea intervention to parents/ } \\
\text { caregivers in their own settings. }\end{array}$ \\
\hline \multirow[t]{2}{*}{ Acceptability } & $\begin{array}{l}\text { Parents and professionals opinions of the SafeTea } \\
\text { campaign and materials }\end{array}$ & $\begin{array}{l}\text { Any comments regarding parents and professionals opinions (positive or negative) of the } \\
\text { SafeTea campaign or materials. }\end{array}$ \\
\hline & Suggestions for improvement & Any comments about the ways in which the SafeTea campaign could be improved. \\
\hline \multirow[t]{3}{*}{$\begin{array}{l}\text { Impact/behavioural } \\
\text { change }\end{array}$} & $\begin{array}{l}\text { Awareness/education of the risk of scalds to young } \\
\text { children from hot drinks and of appropriate burn } \\
\text { first aid }\end{array}$ & $\begin{array}{l}\text { Any remarks about whether the SafeTea campaign has raised parents' awareness of the risk of } \\
\text { hot drink scalds to young children or succeeded in educating parents about the risks, and about } \\
\text { appropriate burn first aid. }\end{array}$ \\
\hline & Knowledge of correct burn first aid practices & $\begin{array}{l}\text { Any remarks about whether the SafeTea campaign has affected parents' knowledge of the } \\
\text { correct burn first aid to administer in the event of a burn. }\end{array}$ \\
\hline & Responses to the SafeTea materials and messages & $\begin{array}{l}\text { Any comments regarding parents' reactions to the SafeTea materials, or about how the SafeTea } \\
\text { campaign has affected parents and professionals behaviour with hot drinks around children. }\end{array}$ \\
\hline
\end{tabular}


Box 2 Selected quotes from the qualitative analysis of survey respondents and social media users comments on the SafeTea campaign and materials

\section{Reach of the SafeTea campaign}

\section{Professionals proactivity in spreading the SafeTea messages}

- I'm a childminder and mum. This was very well designed and I was able to give parents a magnet each to help them remember the action plan for burns. I also shared the website link with fellow childminders. Respondent 73, Childminder

- We shared it on our social media group page and sign-posted parents to the website for further information, this allowed them to share it on with their friends and families. Respondent 162, Nursery Employee

- I gave one of the leaflets to a Soft Play that I go to and they requested their own pack and have the poster, flyer and magnet on display. Respondent 71, Childminder

- If you are a parent, work with children or interested in \#BurnsPrevention! Follow @SafeTeaCampaign and check out https://safetea. org.uk for some really useful information \& resources on how to prevent hot drinks burns to kids. Twitter User

Longevity of the SafeTea campaign

- We have kept the poster up to keep reminding parents to keep their hot drinks away from the toddlers. Respondent 27, Baby and Toddler Group Leader

- I laminated the poster and still display it on my courses. Respondent 81, Training Provider

Professionals use of initiative in spreading the SafeTea messages

- We photocopied the flyers and made them available for parents to bring home to read and share. Respondent 86, Children's Centre Employee

- We have secured funding to get the reach charts printed locally and to use as a resource across our Trust area. Respondent 125 , Community Health Improvement Officer

Engagement with the SafeTea campaign

Parents and children's engagement with the SafeTea campaign

- I stuck the reach chart on the wall, each child measured how tall they are, and then on tip toes how high they could reach. It's still there now, the children regularly see if they can beat their record and pretend to burn their fingers and become doctors, it's a brilliant role play starter. Respondent 55 , Childminder

- The children were very interested in the poster and even those who can't yet read were working out what it was all about, before I explained. Respondent 38, Childminder

Components of the SafeTea intervention (printed materials, activities, videos) that parents and professionals were most engaged with

- The layout/text and colours made the poster attractive to read and attracted attention. Respondent 151, Burns Unit Employee

- I absolutely love the magnets, they are visual, clear, concise, and easy to read. Respondent 146, Support Worker

- Great film, really brings home the dangers of burns. Facebook User comment on prevention video

- Flyers are a good idea but we are reliant on parents reading, understanding and remembering the information. Respondent 11, Youth Welfare Officer

- Unfortunately I didn't have time to incorporate the activities into my existing teaching, however it's something I will hold onto and possibly use in the future. Respondent 66, First Aid Instructor

Acceptability of the SafeTea campaign and materials

Parents and professionals opinions of the SafeTea campaign and materials

- I think the concept and the materials provided are really good. Respondent 3, First Aid Instructor

- This was a good campaign that had sensible information. Respondent 145, Childminder

- The SafeTea Campaign have multiple fantastic resources to support your burn awareness training. Twitter User

- The answer is simple. Obviously follow the 'common sense' tips given above, but perhaps pay more attention to the children and perhaps a little less to your mobile phones. Facebook User

- I disagree [with the first aid advice], I took clothing off my son after soaking and was told in the burns unit that I shouldn't have as it made things worse. Facebook User

Clarity and comprehensibility of content in SafeTea materials

- Some of our families have English as a second language but I felt the poster was suitable for all. Respondent 11, Youth Welfare Officer

- The poster gets the message over to parents and health workers very well. Respondent 32, Paediatric Specialist

- There are clear pictures depicting the dangers of hot drinks. Respondent 33, Nursery Employee

- The flyer gives clear methods for parents and carers to use when a burn has happened. Respondent 107, Nursery Employee

Use of SafeTea materials for facilitating communication between professionals and parents

- I'm very impressed with your resources and this campaign -it has helped as a prompt for health visitors to discuss burns prevention and is a great visual aid for parents. Respondent 84 , Health Visitor

- The campaign was excellent, it really was useful for follow-up appointments with families regarding accident prevention. Respondent 109, Health Visitor

- The posters and other resources were great for starting conversations with parents within the centre and when family support workers visited families. Respondent 86, Children's Centre Employee

Impact/behavioural change

Awareness/education of the risk of hot drinks scalds to young children and of appropriate burn first aid 


\section{Box 2 Continued}

- My son had a near miss burn in day care and this campaign has definitely assisted in educating staff and other parents of the risks. Respondent 60, Parent

- I thought this campaign was excellent. I discussed it with my parents, one admitted she wouldn't really have known what to do if her child poured hot tea or coffee on himself. I educated her and recommended a parents first aid course. Respondent 5, Childminder

- The message of first aid appears to be getting through. Respondent 78, Paediatric Specialist

Knowledge of correct burn first aid practices

- The children look at and talk about the poster most days as it's on the back of the front door so it's a constant reminder about the dangers of hot drinks and why they must not touch hot drinks... The two threeyear-olds have taken the information in from the magnet on the fridge and know how to call 999 and put the burn under cold water. It's been a very useful pack. Respondent 71, Childminder

- A lot of parents were originally unaware of the need to cool the burned area and that they should not apply creams prior to A\&E assessment. Respondent 134, Health Visitor

Responses to the SafeTea materials and messages

- A parent straight away saw the poster and said 'oh gosh, I must stop having hot drinks near my child'. Respondent 28, Childminder

- My parent was shocked when I told her that her son could reach my kitchen side and she hadn't realised he could also reach hers. Respondent 5, Childminder

- People were surprised how long a cup of tea stays hot. Respondent 53, Children's Centre Employee

- I feel parents and children take more notice of the height chart and I often see parents measuring their children against it surprised to see how far their child can actually reach. Respondent 155, Children's Centre Employee

- I got each child to demonstrate their reach and this really brought to my attention that I need to move things even further away although I try to use travel mugs. Respondent 40, Childminder

- Unfortunately parents don't always realise the dangers until an accident happens. The parents looked at the magnets and the reach chart but didn't seem to take the warnings seriously. I think most parents were rather blasé about the dangers! Respondent 30, Baby and Toddler Group Leader

national and local radio and television news channels, in newspapers, the online press, articles and blogs, magazines and health/ injury prevention newsletters and bulletins (online supplemental appendix 4). SafeTea reached an average of 9500 UK parents daily on Facebook (84\% were women mostly 25-44 years old), more than the 5500 anticipated (figure 4), however, reach and impression rates steadily decreased after NBAD. Videos were viewed over 400000 times. The Mumsnet adverts appeared on 27781 visitors' screens. Social media users and website visitors originated from across the UK; most website visitors were from London (11\%), Cardiff (8\%) and Bristol (3\%).

SafeTea resource packs (577) were requested by 472 professionals, and sent out by post. Of these 472 professionals, $405(86 \%)$ consented to receiving the survey, and $163(40 \%)$ completed it. Professionals were predominantly childminders, health visitors and nursery staff (online supplemental appendix 5) and were proactive in sharing the SafeTea materials with parents and colleagues and spreading the SafeTea messages (box 2). One paediatrician stated: 'I used the resources myself in a toddler group and I emailed the link to the SafeTea website to all health visitors, paediatric consultants and juniors in the Health Board'.

Of the 93\% (151/163) who used the materials with parents, most estimated that they reached between 1 and 10 parents, however, 10\% (15/151) reached more than 100 parents. Many professionals reported that they continued to display the materials around their workplaces and use them in educational sessions, thereby increasing the longevity of the campaign. Organisations used their own initiative to continue using and distributing the materials, for example, by securing funding to print materials.

\section{Engagement with the SafeTea campaign}

Facebook and Twitter users and website visitors engaged well with the campaign (figure 4). Engagement on Instagram was poor from the outset and was deemed unviable for the campaign and abandoned after 3 weeks. There were regular peaks of Facebook followers throughout the campaign, with few unfollows. Many

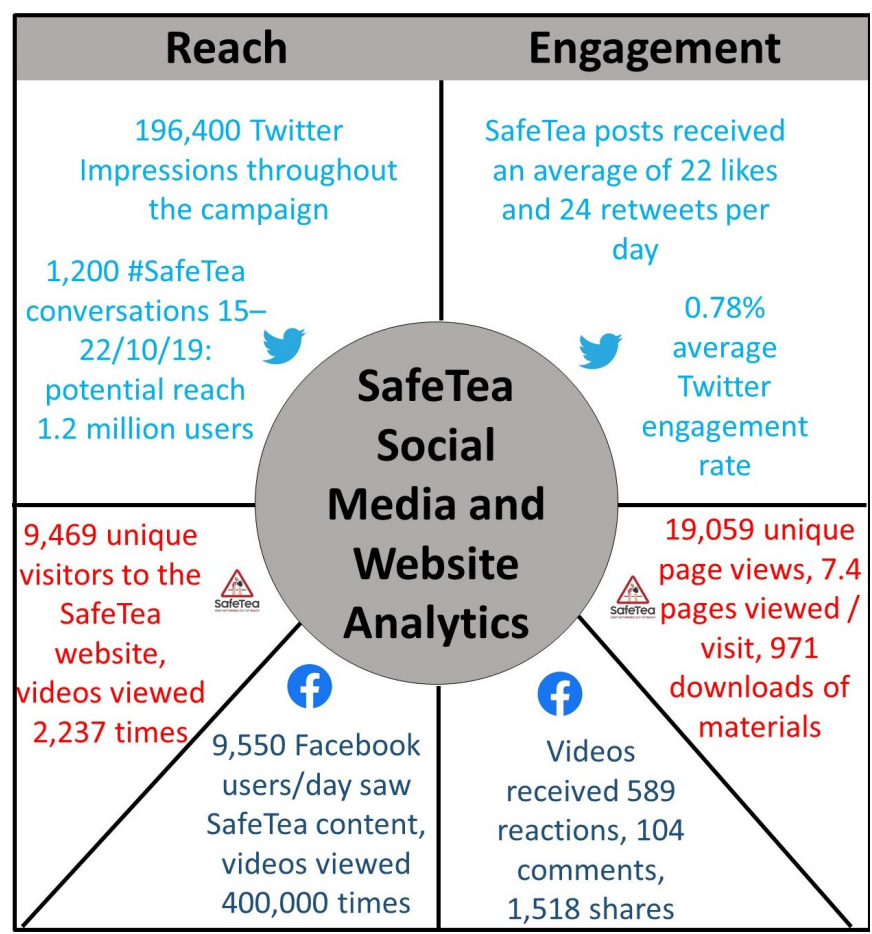

Figure 4 Key reach and engagement metrics for the SafeTea campaign. Unique visitors to the SafeTea website are the number of people who visited the website at least once during the campaign period. Unique page views are the number of visits to the website during which an individual page was viewed at least once. 
parents shared personal stories of children's burns. Engagement rates on Twitter were high initially (1.60\% in October), but steadily decreased to $0.70 \%$ in November, and $0.40 \%$ in December and January; the average engagement rate across the campaign was $0.78 \%$. Although not definitive, a Twitter engagement rate between $0.09 \%$ and $0.33 \%$ is considered to be high, and the median engagement rate across every industry is $0.045 \% .^{34}$

On Mumsnet, two SafeTea adverts received higher engagement than any other advert on Mumsnet at the time. The components of the social media campaign that generated the most engagement were: the launch on NBAD; stories posted by parents; posts accompanied by images and videos; and factual posts with an emotive angle. Posts consisting of mainly statistics for example, ' 30 babies and toddlers go to the hospital with a hot drink burn every day', generated comparatively less engagement and page views. Most website visits (62\%) originated from social media and $97 \%$ of these originated from Facebook. Most users accessed the website via their mobile (57\%) and visited the resources pages ( $>24000$ page views).

Professionals mainly reported using the materials directly with families. Posters were used by $95 \%$ of professionals; flyers by $93 \%$; magnets by $86 \%$; reach charts by $69 \%$; activity sheets by $54 \%$; and videos by $24 \%$. Professionals felt that parents and children engaged with the posters, magnets and reach charts and that they were interested in improving their knowledge around burns prevention and first aid (box 2). As one health visitor remarked: 'The posters have quickly caught parents' attention when in clinic and at groups'. Another observed: 'Parents were very interested in developing their knowledge'. However, some professionals commented that they did not have time to deliver interactive demonstrations or discuss the information in the flyers with parents. While the SafeTea videos were perceived as a potentially powerful teaching resource, professionals reported lack of technology as a barrier to sharing them.

\section{Acceptability of the SafeTea campaign and materials}

SafeTea users' opinions of the campaign and materials were extremely positive (box 2). One Facebook user commented: 'SafeTea are doing great work on prevention and first aid awareness of burns in young children'. There were surprisingly few negative comments on social media. Two parents on Facebook expressed the view that the prevention advice was obvious, while another questioned the accuracy of the first aid advice, which encouraged debate and eventually clarification from a burns surgeon. Professionals praised the materials' visual appeal, clarity and ease of understanding. Over $87 \%$ of professionals rated the materials as 'excellent' or 'good' and over 97\% felt they were 'definitely' or 'probably' easily understood by parents. Some professionals suggested producing resources in additional languages, and many wanted more hard copies of the leaflets and magnets to distribute.

\section{Impact/behavioural change}

The professionals who completed the survey reported increased awareness of the dangers of hot drinks and the benefits of appropriate first aid among parents and believed that the campaign improved children's and parents' knowledge of correct first aid for burns (box 2). One nursery employee remarked: 'I feel that all parents, professionals and adults entering the building now have a better awareness'. Another stated: 'Many parents were not aware of how long they should cool the burn for and that they should use cling film to cover the burn'. Increased awareness and knowledge was partially attributed to the fact that materials on display act as a constant reminder, thereby facilitating information retention.

Professionals noted that the materials invoked strong reactions in some parents, and that many were surprised to see how high their child could reach. Professionals felt that the posters and reach charts were particularly useful resources for encouraging parents to think about the risks associated with hot drinks. One childminder remarked: 'I think the reach chart helped to make a few parents realise what children could do and stopped them leaving hot drinks in silly places'. The campaign led to parents and professionals discussing how to change their behaviours to minimise risk (box 2). One children's centre employee commented: 'I spoke to parents about SafeTea and this made us make a decision not to have tea in our setting when children are present'. One baby and toddler group leader was sceptical of the ability of SafeTea to change parents' behaviours with hot drinks.

\section{DISCUSSION}

This process evaluation suggests that the SafeTea campaign was successful in reaching a large number of the target audience of parents/caregivers of young children and professionals working with these parents/caregivers across the UK. Parents and professionals engaged with SafeTea both online and in community settings, and expressed positive opinions of the campaign and materials. The findings reinforce those from the feasibility study that the SafeTea materials were acceptable and easily understood, and have the potential to change caregivers' behaviours with regard to hot drink scalds prevention and burn first aid. ${ }^{20}$ The acceptability and efficacy of SafeTea were thus maintained following online adaptation, and the online delivery mechanism enabled nationwide dissemination of key messages, and accessibility of the materials to a wide variety of health professionals and community practitioners.

To our knowledge, SafeTea is one of only two interventions aimed at both preventing hot drink scalds in young children and improving caregiver knowledge of correct burn first aid. ${ }^{16-18} \mathrm{~A}$ randomised controlled trial of Cool Runnings, ${ }^{35}$ a mobile appbased intervention that used social media to recruit mothers of young children in Australia, ${ }^{36}$ found that the intervention was effective for improving mothers' knowledge about risks of hot drink scalds and burn first aid. ${ }^{35}$ While we did not directly measure improvements in knowledge among parents, these results confirm those of the SafeTea feasibility study, ${ }^{20}$ in which parents' perceived risk of hot drink scalds and knowledge of correct first aid procedures improved postintervention. A mobile app containing the SafeTea messages and materials could be considered as a potential delivery channel for future campaigns.

Although research evaluating the effectiveness of parent education on scald prevention in preschool children is scarce, ${ }^{16}{ }^{17}$ systematic reviews and meta-analyses suggest that multimedia campaigns and online interventions are effective at influencing behaviour change across a range of issues including alcohol consumption, tobacco use and physical activity. ${ }^{373}$ The evidence indicates that effective behaviour change interventions are multifaceted and underpinned by theory, and that shorter interventions offer larger impacts. ${ }^{3738}$

Launching SafeTea on NBAD and coordinating the launch with the Children's Burns Trust was critical for optimising publicity. Regional press and media coverage was effective in Cardiff and Bristol where the project team were based; a more widespread publicity campaign with local case studies in other UK regions may have widened the reach. Reach, impression and 
engagement rates and website visits were highest in the first week and were maintained for the first month of the campaign, falling off thereafter. This was likely related to the reduced publicity, and the reduced frequency of social media posts from November onwards, due to a lack of fresh content to post. This demonstrates the importance of continually generating and posting new social media content, and suggests that the campaign could be equally effective over a shorter time period using additional and more frequent social media posts.

Part of the campaign strategy was to guide social media users to the SafeTea website and the downloadable materials. Given that most website users originated from social media platforms, this strategy was clearly effective. Most of this traffic came from Facebook, with a small proportion originating from Twitter. It is possible that Twitter users were not using the materials to deliver the intervention in their settings but were promoting the key messages in a supportive role. It became clear early on that Instagram was not a viable platform for the campaign, probably due to the lack of influencers or brands to work with, and because the SafeTea posts and messaging were not aesthetically appealing.

The strengths of this study are in the use of theory, and of mixed methods and triangulation of data from different sources, which enabled us to increase the scope and depth of the findings and enhance confidence in our conclusions and recommendations. The evaluation was limited because it was difficult to determine precisely how many people the SafeTea campaign reached, and it was not possible to directly measure behaviour change among parents and caregivers. The ability to reach a wide audience is a strength of a multimedia campaign, however paradoxically this also presents the greatest challenge for evaluation. ${ }^{22}$ It is difficult to reach and follow-up the target audience as there is little control over who is exposed to the campaign. ${ }^{22}$ The analysis was limited by the information that social media and Google Analytics provides: for example, Google Analytics only provides demographic information if a user is logged into their Google account. The $40 \%$ of survey respondents were likely those who found the materials beneficial, therefore, the survey results should be interpreted with some degree of caution.

\section{Recommendations}

Any future SafeTea campaign should be shorter and more widely advertised in all UK countries. Taken together, the findings from the feasibility study ${ }^{20}$ and the campaign process evaluation demonstrate the potential for SafeTea to achieve the intermediate outcomes described in the logic model (figure 1); that is, increase parents perceived risk of hot drink scalds in preschool children, improve their knowledge of appropriate burn first aid, and encourage them to change their behaviours to minimise risk. Future research should focus on assessing behavioural change directly with parents. In order to measure whether SafeTea is effective in achieving the long-term intended outcomes of reducing the incidence of scalds in preschool children, reducing burn severity and improving burn first aid administration, attention must be given to an evaluation of the epidemiology of hot drink scalds and burn first aid practices over and beyond the time-frame of the campaign. This will require continued surveillance of burns presentations to hospitals, and could be facilitated using the Burns and Scalds Assessment Template, an evidence-based data collection proforma designed to standardise the clinical assessment of childhood burns in the emergency department. ${ }^{39}$ The SafeTea campaign strategy and materials are now validated for use with an online population and could be used in future burns awareness campaigns. The materials will remain on the SafeTea website for the foreseeable future.

\section{CONCLUSIONS}

The SafeTea multimedia campaign reached a greater number of the target audience (young parents and professionals working with families) with a limited budget in comparison to what is possible in local, face-to-face community-based campaigns. Collaboration with NBAD enabled us to capitalise on an established 'National Day' with its associated television, radio and news publicity, which significantly enhanced the campaign promotion. Engagement with parents and professionals was successful and they had high opinions of the SafeTea campaign and materials. A shorter campaign is advisable and could be run again alongside $\mathrm{NBAD}$ as the resources remain current. A future campaign would benefit from funding for a full-time staff member to coordinate the social media component.

\section{What is already known on the subject}

- Scalds from hot drinks are the leading cause of burns in children less than 5 years old and parents lack knowledge of appropriate first aid for burns.

- SafeTea is a multifaceted intervention that aims to prevent hot drink scalds to young children and improve parents' knowledge of appropriate burn first aid.

- The delivery of SafeTea by community practitioners is feasible and the intervention materials and teaching methods are acceptable to both parents and practitioners.

\section{What this study adds}

SafeTea was adapted for a national integrated multimedia campaign that was launched on National Burns Awareness Day 2019 and ran for 3 months.

- This mixed-methods process evaluation using data from multiple sources showed that the SafeTea campaign was successful with a good reach, and that parents and professionals were engaged with the campaign and had high opinions of the campaign and materials.

- The launch on National Burns Awareness Day was critical for optimising publicity. However, a future campaign could run for a shorter period of time using additional social media content, more frequent posting and more funding for social media coordination and promotion.

Acknowledgements We would like to thank the funders, our SafeTea ambassadors, and our collaborating partners on the steering group, especially Kate Rivera at Raw Marketing and Alison Tweddle at the Children's Burns Trust. Thanks to parents and staff of Flying Start in Cardiff and the Vale of Glamorgan for their valuable contribution to the design and development of the campaign materials, Beagle Media for video production, Eleanor Carden at The Scar Free Foundation for her work on the social media campaign, Howard Bowden for his help coordinating publicity around NBAD, Adam Jones for original graphics and drawings, Jack Godfrey for final graphical design, and Steffan Williams for creating the SafeTea website.

Contributors LEC extracted the website usage data from Google Analytics, analysed the survey data and social media comments, integrated all of the results using data triangulation, contributed to the interpretation and discussion of the findings, produced all of the tables and figures, drafted the initial manuscript and revised the manuscript. CVB made substantial contributions to the conceptualisation and design of the study and the design and development of the SafeTea campaign and revised the manuscript. IB managed the social media accounts, conducted an evaluation of the social media data and extracted the key social media metrics, contributed to the interpretation and discussion of the findings and revised the 
manuscript. AE and AMK conceptualised the study, contributed to the design of the study and the design and development of the SafeTea campaign, contributed to the interpretation and discussion of the findings and revised the manuscript. All authors approved the final manuscript.

Funding This research was supported by funding from The Scar Free Foundation (no award/grant number), Health and Care Research Wales (no award/grant number), the Cardiff University City Region Exchange (no award/grant number), the Vocational Training Charitable Trust (VTCT) Foundation (no award/grant number), the Worshipful Company of Tinplate Workers (no award/grant number) and the British Burn Association (no award/grant number).

Competing interests None declared.

Patient consent for publication Not required.

Ethics approval The evaluation study was approved by the Cardiff University Research Ethics Committee on 23 July 2019 (reference number 19/61). Personal information was used in accordance with the General Data Protection Regulation (GDPR) 2018.

Provenance and peer review Not commissioned; externally peer reviewed.

Data availability statement All data relevant to the study are included in the article or uploaded as online supplemental information.

Supplemental material This content has been supplied by the author(s). It has not been vetted by BMJ Publishing Group Limited (BMJ) and may not have been peer-reviewed. Any opinions or recommendations discussed are solely those of the author(s) and are not endorsed by BMJ. BMJ disclaims all liability and responsibility arising from any reliance placed on the content. Where the content includes any translated material, BMJ does not warrant the accuracy and reliability of the translations (including but not limited to local regulations, clinical guidelines, terminology, drug names and drug dosages), and is not responsible for any error and/or omissions arising from translation and adaptation or otherwise.

Open access This is an open access article distributed in accordance with the Creative Commons Attribution Non Commercial (CC BY-NC 4.0) license, which permits others to distribute, remix, adapt, build upon this work non-commercially, and license their derivative works on different terms, provided the original work is properly cited, appropriate credit is given, any changes made indicated, and the use is non-commercial. See: http://creativecommons.org/licenses/by-nc/4.0/.

\section{ORCID iDs}

Laura Elizabeth Cowley http://orcid.org/0000-0002-7757-4219

C Verity Bennett http://orcid.org/0000-0002-9311-4124

Alison Mary Kemp http://orcid.org/0000-0002-1359-7948

\section{REFERENCES}

1 Kemp AM, Jones S, Lawson Z, et al. Patterns of burns and scalds in children. Arch Dis Child 2014;99:316-21.

2 Dewar DJ, Magson CL, Fraser JF, et al. Hot beverage scalds in Australian children. J Burn Care Rehabil 2004;25:224-7.

3 Burgess JD, Kimble RM, Cameron CM, et al. Hot beverage scalds in Australian children: still simmering 10 years on. J Burn Care Res 2016;37:e335-9.

4 Davies $\mathrm{K}$, Johnson EL, Hollén $\mathrm{L}$, et al. Incidence of medically attended paediatric burns across the UK. Inj Prev 2020;26:24-30.

5 Bakker A, Maertens KJP, Van Son MJM, et al. Psychological consequences of pediatric burns from a child and family perspective: a review of the empirical literature. Clin Psychol Rev 2013;33:361-71.

6 Duke JM, Randall SM, Vetrichevvel TP, et al. Long-Term mental health outcomes after unintentional burns sustained during childhood: a retrospective cohort study. Burns Trauma 2018:6:1-10

7 Harish V, Tiwari N, Fisher OM, et al. First aid improves clinical outcomes in burn injuries: evidence from a cohort study of 4918 patients. Burns 2019:45:433-9.

8 Bennett CV, Maguire S, Nuttall D, et al. First aid for children's burns in the US and UK an urgent call to establish and promote international standards. Burns 2019;45:440-9.

9 Varley A, Sarginson J, Young A. British burns association first aid position statement, 2014. Available: https://www.salisbury.nhs.uk/LookingAfterYourself/PreventionOf BurnsAndScalds/Document s/BBA\%20First\%20Aid\%20Position\%20Statement.pdf [Accessed 1 Jul 2020].

10 Burgess JD, Kimble RM, Watt KA, et al. Hot tea and tiny tots don't mix: A crosssectional survey on hot beverage scalds. Burns 2017;43:1809-16.
11 Davies M, Maguire S, Okolie C, et al. How much do parents know about first aid for burns? Burns 2013:39:1083-90.

12 Alomar M, Rouqi FA, Eldali A. Knowledge, attitude, and belief regarding burn first aid among caregivers attending pediatric emergency medicine departments. Burns 2016;42:938-43

13 Frear CC, Griffin B, Watt K, et al. Barriers to adequate first aid for paediatric burns at the scene of the injury. Health Promot J Austr 2018;29:160-6.

14 Burgess JD, Cameron CM, Cuttle L, et al. Inaccurate, inadequate and inconsistent: a content analysis of burn first aid information online. Burns 2016;42:1671-7.

15 Tiller $G$, Rea S, Silla R, et al. Burns first aid information on the Internet. Burns 2006:32:897-901.

16 Turner C, Spinks A, McClure R, et al. Community-Based interventions for the prevention of burns and scalds in children. Cochrane Database Syst Rev 2004:CD004335

17 Zou K, Wynn PM, Miller P, et al. Preventing childhood scalds within the home: overview of systematic reviews and a systematic review of primary studies. Burns 2015;41:907-24

18 Burgess JD, Watt KA, Kimble RM, et al. Knowledge of childhood burn risks and burn first aid: cool Runnings. Inj Prev 2019;25:301-6.

19 Nurmatov UB, Mullen S, Quinn-Scoggins $H$, et al. The effectiveness and costeffectiveness of first aid interventions for burns given to caregivers of children: a systematic review. Burns 2018;44:512-23.

20 Bennett CV, Hollén L, Quinn-Scoggins HD, et al. Feasibility of Safe-Tea: a parenttargeted intervention to prevent hot drink scalds in preschool children. Inj Prev 2020;26:31-41.

21 Moore GF, Audrey S, Barker M, et al. Process evaluation of complex interventions: medical Research Council guidance. BMJ 2015;350:h1258.

22 Wellings K, Macdowall W. Evaluating mass media approaches to health promotion: a review of methods. Health Educ 2000;100:23-32.

23 Neiger BL, Thackeray R, Van Wagenen SA, et al. Use of social media in health promotion: purposes, key performance indicators, and evaluation metrics. Health Promot Pract 2012;13:159-64.

24 Crutzen R, Roosjen JL, Poelman J. Using Google analytics as a process evaluation method for internet-delivered interventions: an example on sexual health. Health Promot Int 2013;28:36-42.

25 Champion V, Skinner CT. The health belief model. In: Glanz K, Rimer BKV, eds. Health behavior and health education: theory, research, and practice. 4 ed. San Francisco, USA: Jossey-Bass, 2008.

26 Conner M, Norman P. Predicting health behaviour: research and practice with social cognition models. 2nd edn. McGraw-Hill Education, UK: Open University Press, 2005.

27 Bandura A. National Institute of mental health. social foundations of thought and action: a social cognitive theory. Englewood Cliffs, NJ, US: Prentice-Hall, Inc, 1986

28 Pershad $\mathrm{Y}$, Hangge $\mathrm{P}$, Albadawi $\mathrm{H}$, et al. Social medicine: Twitter in healthcare. J Clin Med 2018;7:121.

29 Duggan M, Lenhart A, Lampe C, et al. Parents and social media. Pew research center, 2015. Available: https://www.pewresearch.org/internet/2015/07/16/parents-andsocial-media [Accessed 23 Aug 2020]

30 Fernandez ME, Ruiter RAC, Markham CM, et al. Intervention mapping: theory- and evidence-based health promotion program planning: perspective and examples. Front Public Health 2019;7:209.

$31 O^{\prime}$ Cathain A, Murphy E, Nicholl J. Three techniques for integrating data in mixed methods studies. BMJ 2010:341:c4587.

32 Heale R, Forbes D. Understanding triangulation in research. Evid Based Nurs 2013;16:98.

33 Braun V, Clarke V. Using thematic analysis in psychology. Qual Res Psychol 2006:3:77-101.

34 Feehan B, Rival IQ. 2020 social media industry benchmark report, 2020. Available: https://www.rivaliq.com/blog/social-media-industry-benchmark-report/2020 [Accessed 1 Jul 2020].

35 Burgess J, Watt K, Kimble RM, et al. Combining technology and research to prevent scald injuries (the cool Runnings intervention): randomized controlled trial. J Med Internet Res 2018:20:e10361.

36 Burgess JD, Kimble RM, Watt K, et al. The adoption of social media to recruit participants for the cool Runnings randomized controlled trial in Australia. JMIR Res Protoc 2017;6:e200.

37 Stead M, Gordon R, Angus K, et al. A systematic review of social marketing effectiveness. Health Educ 2007;107:126-91.

38 Cugelman B, Thelwall M, Dawes P. Online interventions for social marketing health behavior change campaigns: a meta-analysis of psychological architectures and adherence factors. J Med Internet Res 2011;13:e17.

39 Hepburn K, Bennett V, Kemp AM, et al. Burns and scalds assessment template: standardising clinical assessment of childhood burns in the emergency department. Emerg Med J 2020;37:351-4. 